\title{
Analysis of dynamic decision-making in a bicycle-sharing auction using a dynamic discrete choice model
}

\author{
Yusuke Hara $^{1}$ (D) Eiji Hato ${ }^{1}$
}

Published online: 11 July 2017

(C) The Author(s) 2017. This article is an open access publication

\begin{abstract}
For clarifying the usefulness and practical issues of a tradable permit system empirically, we implemented a tradable permit system for a bicycle-sharing service in Yokohama city, Japan. We analyzed both travel and transaction behavior within this system. Many activity factors, such as the amount of free time in each day, home location and travel mode to the bicycle port, were shown to affect the transaction of tradable permits. The results of the pilot program indicated that inefficient allocation of tradable permits occurred when participants postponed their decision-making because of uncertainty. To determine the reason for this effect and the contributing factors, we created a dynamic discrete choice model to describe the choice results and timing. The estimation result indicated that the option value of postponing decision-making caused the transactions to be performed at the last minute, and that this effect blocked the liquidity of the permits trade. In addition, because the result reveals that there was heterogeneity in the time discount factor, the initial allocation of permits was found to be important for efficient allocation.
\end{abstract}

Keywords Dynamic discrete choice model - Tradable permit system · Dynamics of travel behavior $\cdot$ Bicycle-sharing system

\section{Introduction}

Demand forecasting, pricing, and mechanism design are all important research topics in transportation planning. Developments in information and communication technology enable us to collect user travel behavior data in detail and design complex systems for

Yusuke Hara

hara@bin.t.u-tokyo.ac.jp

1 Department of Civil Engineering, The University of Tokyo, 7-3-1 Hongo, Bunkyo-ku, Tokyo, Japan 
transportation services. The empirical study of new pricing systems and mechanism design is needed to validate whether these systems perform efficiently. Analysis of travel behavior under a novel transportation system is also important because such behavior usually varies across users.

To achieve policy goals, which means efficient use of transportation system, without monitoring the private value that users placed upon their time or upon transportation services, the tradable credit scheme model has been proposed (Verhoef et al. 1997; Viegas 2001; Yang and Wang 2011; Wu et al. 2012; Nie and Yin 2013). According to this scheme, credits were distributed by the government and users were then required to pay a certain number of credits to use transportation services and facilities. The credits could be traded among users and the price was determined by the market through free trading. By deciding the initial credit distribution, the government could achieve its policy goal. The major advantage of the tradable credit scheme was the achievement of efficient allocation by free trading without requiring information about user preferences.

In this study, we implemented a tradable permit system for bicycle-sharing service to clarify the usefulness and practical issues of a tradable permit system empirically. In particular, permits for using the bicycle-sharing service were distributed to users, and we attempted to allocate them efficiently through free trading. Our objective is validating tradable credit/permit schemes, which had been validated only by theoretical approach, by a social pilot program empirically. If the social pilot program show some practical issues of these schemes, then we can improve the scheme practically.

Our key contributions are as follows:

- We implemented a tradable permit system in Yokohama city as a social pilot program. It is a new attempt even from a global perspective. Although there are many existing studies of transportation service auction by theoretical approaches, there is no empirical study of transportation service auction. The empirical transaction behavior is valuable.

- We collected both transaction behavior in the transportation service auction and travel behavior by GPS every day in the social pilot program. These data can clarify the relationship between transaction of tradable permit and day-to-day travel behavior.

- We did not use real money but a "virtual money" in the social pilot program. However, we designed the incentive compatible social pilot program by the induced value theory of experimental economics.

- We discovered that a tradable permit system for a transportation service cannot necessarily achieve the efficient allocation that the theoretical analysis forecasts though the sample size of our pilot program is small. In particular, the transaction behavior of tradable permits is a type of reservation behavior under uncertainty and, in reality, users postponed their decision-making and changed their schedule without prior warning. We showed empirically that this behavior is one of the causes that the tradable permit system in our pilot program did not work.

- By using a dynamic discrete choice model, we modeled the decision-making of tradable permit transaction, and we empirically clarified the important elements about transaction and future decision-making.

The rest of this paper is organized as follows. "Related work" section reviews the reservation system, the pricing system, and the tradable credit/permit scheme for transportation service. In addition, we review the dynamic discrete choice model for describing 
dynamic decision-making. "Pilot program and Data" section describes the pilot program in Yokohama city in detail and summarizes our data. "Basic analysis" section presents the basic analysis to clarify the relationship between transaction behavior and travel behavior. "Dynamic discrete choice modeling for choice dynamics" section formulates the dynamic discrete choice model for choice dynamics. In "The estimation result of the dynamic discrete choice model anddiscussion" section, we estimate the parameters of the dynamic discrete choice model, and sensitivity analysis is described in "Sensitivity analysis" section. Finally, "Conclusions" section concludes the paper.

\section{Related work}

Let us begin by reviewing the reservation and tradable permit system of modes of transportation for efficient use. The transportation reservation system (for modes such as railway service and airlines) is not new. Akahane and Kuwahara (1996) analyzed the motorway reservation system using a stated preference survey. Wong (1997) described a reservation system for improving the road performance of highways. Teodorovic et al. (2005) and Edara and Teodorovic (2008) proposed a highway space inventory-control system. Yang et al. (2013) analyzed the reservation system for parking spaces for morning commute. Liu et al. (2015) analyzed the efficiency of highway reservation system from the point of user heterogeneity in values of travel time and schedule penalties.

On the other hand, there have been studies that aim to achieve efficient allocation by bidding an individual's own value or trading his/her own rights and permits for a transportation service. One such a scheme is the tradable credit scheme (Verhoef et al. 1997; Viegas 2001; Yang and Wang 2011; Wu et al. 2012; Nie and Yin 2013) and another is the tradable permit system (Akamatsu 2007; Wada and Akamatsu 2013). In tradable mobility credit scheme, the government sets a predetermined congestion reduction goal and tries to achieve it by creating a market for mobility credits. And the government issues mobility credits to all eligible travelers and determines how many credits are to be charged on each road. In tradable permit scheme, the government issues the permits. The number of permits of each road link is determined by the road capacity of each link. The tradable permit scheme does not generate the road congestion because the number of permits is less than the road capacities. And users bid the tradable permits directly in the market. Although there is a subtle difference between two schemes, both these approaches aim to solve problems with user heterogeneity and information asymmetry through market mechanisms. Compared to a reservation system, these schemes can allocate infrastructure capacity efficiently and in detail, but they force users to understand the complex underlying mechanisms. Additionally, there have been no empirical studies to validate these system. This study clarifies the issues surrounding tradable permit system. Nie (2012) and He et al. (2013) both consider the impact of transaction costs on tradable permit schemes. They theoretically show that the consideration of transaction costs makes the outcomes of the system depend on the market arrangement, particularly the initial allocation of mobility credits. Shirmohammadi et al. (2013) consider the impact of uncertainty on tradable permit schemes theoretically. In this paper, we focus on the empirical study of the impact of both transaction cost and the uncertainty on tradable permit schemes. 
Then, let us review the discrete choice model for dynamic decision-making because reservation behavior and bidding behavior for transportation services are future decisionmaking and the timing of the decision-making is also important. Discrete choice model has been used widely in travel demand analysis, marketing, and other areas, and it can explain the choice result on the basis of random utility theory from observed data. Discrete choice models have been generalized and extended. Although the original logit model (McFadden 1974 ) is easy to apply, it has problems with its error structure. Hence, other models, such as the Probit (Daganzo et al. 1977), Nested Logit (Ben-Akiva 1973), generalized extreme value (Vovsha 1997; Ben-Akiva and Bierlaire 1999; Wen and Koppelman 2001), and Mixed Logit (McFadden and Train 2000) models, have been developed. However, the typical discrete choice model is a static model that cannot describe the dynamics of choice behavior along the time axis. Although static discrete choice models are useful for learning the final choice result, they are inadequate for describing the timing of the choice.

Over the past few decades, a considerable number of studies have been made on the inter-temporal decision-making process in economics. These approaches are mainly based on a Markov decision process (MDP). MDP provides a broad framework for modeling sequential decision-making under uncertainty. In labor economics and industrial organization, dynamic discrete choice models have been used for empirical study; this is a dynamic discrete choice model that includes a Markov decision process. Early studies of dynamic discrete choice model were made by Gotz and McCall (1984), Miller (1984), Pakes (1986), Rust (1987), Wolpin (1984, 1987), Das (1992) and Berkovec and Stern (1991). The subjects of those studies included participation behavior in the army, updates of patents, bus engine-replacement, and childbirth decision-making. These studies had timespans ranging from a few months to a few years, and they modeled long-term decisionmaking. In addition, many early studies applied binary choice settings; Rust (1996) was the first to apply multinomial choice setting. There exist survey papers on dynamic discrete choice models, such as those proposed by Eckstein and Wolpin (1989), Puterman (1990), Rust (1994), Rust (1996), Aguirregabiria and Mira (2010).

The major difference between a static discrete choice model and a dynamic discrete choice model is the latent variable for introducing choice probability. Whereas static discrete choice models use the difference between utility functions of alternatives as the latent variable, dynamic discrete choice models use the difference between value functions as the latent variable. Value function is expressed by the sum of the present utility and the present discounted future utilities. Its expression is called the Bellman equation (Bellman 1957). For example, in a static discrete choice model, utility function of alternative $i$ is $U_{i}$. And we assume that each individual maximizes the utility function. In a dynamic discrete choice model, we assume that each individual maximizes value function $v(\cdot)$ and it is expressed as $v\left(s_{i t}\right)=U\left(a_{t}, s_{i t}\right)+\beta \int v\left(s_{i, t+1}\right) d F\left(s_{i, t+1} \mid a_{t}, s_{i t}\right)$, where $v\left(s_{i t}\right)$ is the value function of state $s_{i t}, U\left(a_{t}, s_{i t}\right)$ is the present utility of action $a_{t}$ and state $s_{i t}, a_{t}$ is the action in time period $t, s_{i t}$ is the state in time period $t, F(\cdot)$ is the transition probability distribution, and $\beta$ is the discount factor. Hence, the value function of a dynamic discrete choice model is the sum of the present utility (it is the utility function of a static discrete choice model) and discounted future utility. A static discrete choice model can only express the choice probability at a certain point, whereas a dynamic discrete choice model can express the choice probability of every time period and can describe individual's decision-making considering future decision-making under the uncertainty such as a change of a plan.

For considering future decision-making, dynamic models need to solve dynamic programming problems to compute value functions, and thus have larger computational loads 
than static models. In travel behavior analysis, only a few attempts have so far been made at dynamic discrete choice modeling because of the computational loads. In this paper, we use a dynamic discrete choice model for describing reservation behavior and bidding behavior for transportation services as future decision-making. And we clarify the important elements of the decision-timing empirically.

\section{Pilot program and data}

\section{Implementation of bicycle-sharing auction system}

First, we briefly explain the outline of our pilot program. The bicycle-sharing auction system implemented for this study consists of 4 subsystem: (1) a probe person system; (2) a bicycle-sharing system; (3) a tradable permits system; and (4) an eco point system. As Fig. 1 shows, the 4 subsystems are mutually connected. Travel and activity data of research participants in this pilot program are collected by the probe person system. To use the bicycle-sharing system, participants need bicycle-sharing permits from the tradable permit system and to make a reservation at the bicycle-sharing system. In the payment system for the pilot program, we use eco-points as a virtual currency instead of real money. The participants are given eco-points for their daily eco-friendly travel behavior, such as public transport use or walking trips logged by the probe person system. When participants use their bicycle-sharing permits and make a reservation at the bicycle-sharing system, the bicycle-sharing system sends them a passcode for each bicycle. Hara and Hato (2010) analyzed the same data by basic analysis and static modeling.

The probe person system (Asakura and Hato 2004; Hato and Kitamura 2008) is a method for obtaining travel diary and positioning data in detail using GPS mobile phone. Users operate the mobile phone when they depart and arrive. An application on the mobile phone records data about trip OD, travel mode, trip purpose, time of departure, time of

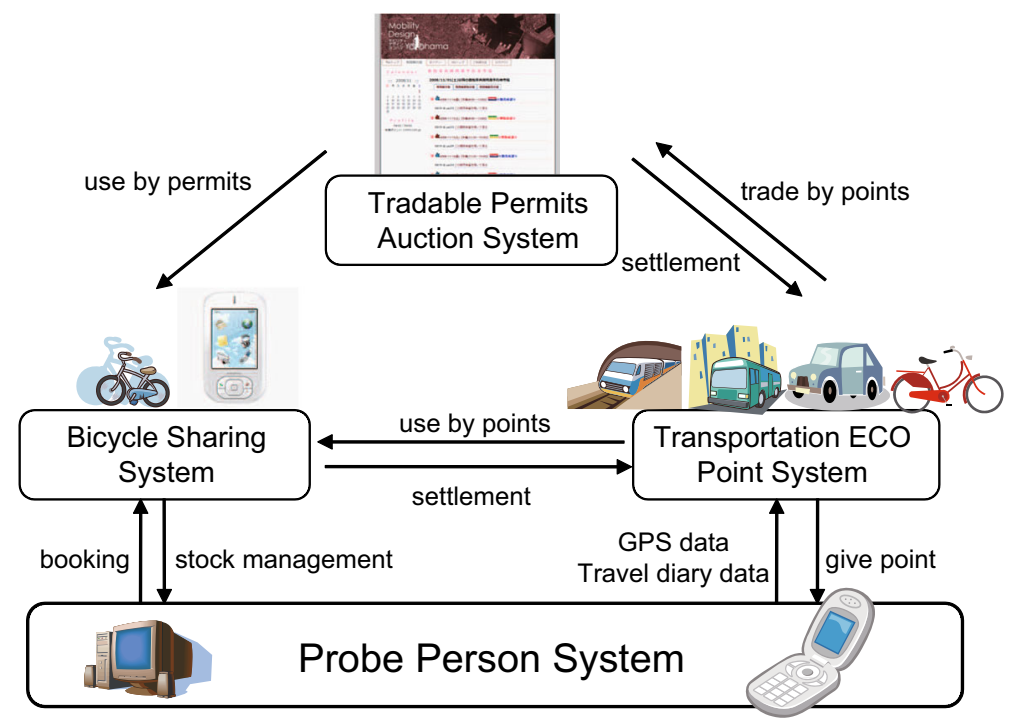

Fig. 1 Total system of this study 
mode change, time of arrival, and location data during the trip. Using a probe person survey, we can collect travel behavior data in greater detail than a paper-based survey.

Then, we introduce a transportation eco-point system. On the basis of the travel behavior of each participant, which is observed by the probe person system, we evaluate the eco-friendliness of each user's behavior. If participants use public transport, walk long distances, or ride with other people, we give them eco-points. The participants can use ecopoints for the bicycle-sharing and tradable permit system, as described previously. Transportation eco-points are not directly exchangeable for real money; however, all participants can obtain survey rewards depending on their collection of eco-points at the end of this survey. For example, the user who has the most eco-points at the end of the survey can obtain the highest survey reward. On the other hand, the user who has the least eco-points can get the least reward. This system is inspired by the induced value theory of experimental economics (Smith 1976). Therefore, our pilot program gives the participants the incentive to regard transportation eco-points as real money despite transportation ecopoints is a "virtual money".

Now let us explain our bicycle-sharing system. Our pilot program implemented two bicycle-sharing systems in the Minato Mirai 21 (MM) area, Yokohama city. MM area is a waterfront urban district in central Yokohama, which contains many offices and commercial facilities. This area is $5 \mathrm{~km} \times 2 \mathrm{~km}$ area. One bicycle-sharing system is the permit system in which users need permits for each time slot. There are two time slots for bicyclesharing: morning (9:30-13:00) and afternoon (13:30-19:00) of each day. Users can go anywhere by bicycle within the time slot. The other system is a first-come first served system in which users can use the bicycle-sharing system if there is no capacity shortage. Users need make a reservation by mobile phone and they can choose their usage time freely. The two bicycle-sharing systems have been implemented separately and the quality of bicycle is different; that is, the bicycles of the permit system are high quality and those of the first-come first-served system are of normal quality, for differentiation. In both bicycle-sharing systems, it is necessary for users to return the sharing-bicycle to the sharing port in MM area.

The tradable permit system is the main subject of our study. We implemented two transaction protocols, a single-auction protocol and a double-auction protocol, for analyzing the effect of auction protocols on user behavior. In single auction, a seller is the administrator of the bicycle-sharing system only and buyers are users (Fig. 2). Each item is a bicycle-sharing permit of a time slot in a day. For example, the system treats the permit of Dec 10th p.m. and the permit of Dec 11th p.m. as different goods. Users have the choice of bidding when they want. As the auction mechanism is set to a second price auction, the highest bidder wins the auction and pays the second-highest price. Vickrey (1961) proves that it is the dominant strategy for bidders to bid their true willingness to pay in the second price auction. In the single auction system, participants can bid the permit by their transportation eco-points. If the participant win the auction, then he/she get the permit and pay the price of the permit by eco-points. In this way, permits are distributed according to each user's willingness to pay.

Single auction achieves an efficient allocation of resources but it is not fair because the users who have little eco points cannot win the auction. Thus, some researchers have suggested a double-auction mechanism as an alternative (for example, Friedman and Rust 1993). A double auction is a process of buying and selling goods when potential buyers submit their bids and potential sellers simultaneously submit their ask prices to an auctioneer. In the permit trading market, all users are buyers and at the same time sellers. In a double auction (Fig. 3), all tradable permits are allocated to all users at random for 


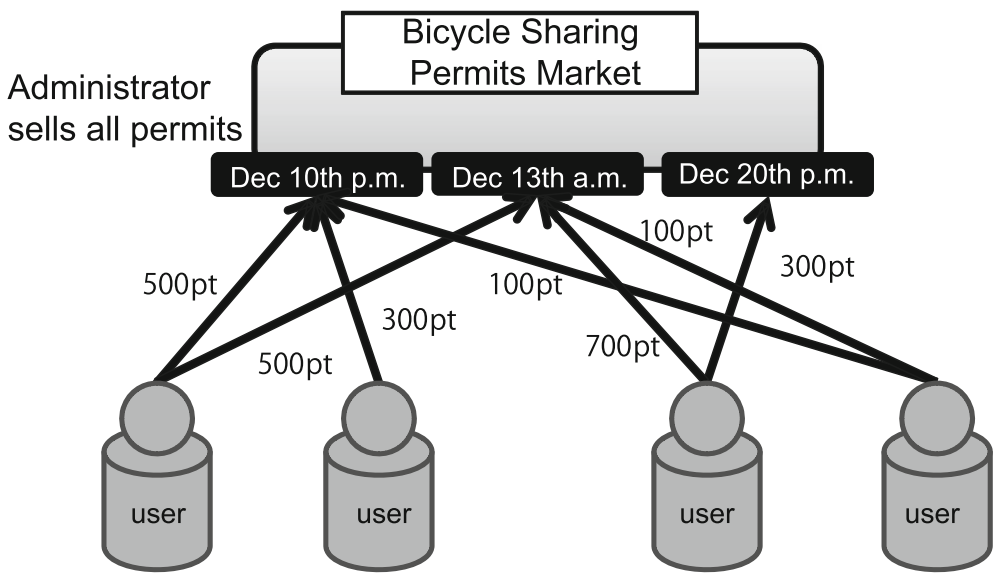

Each user has a bidding choice when he/she wants.

Fig. 2 The image of a single auction system

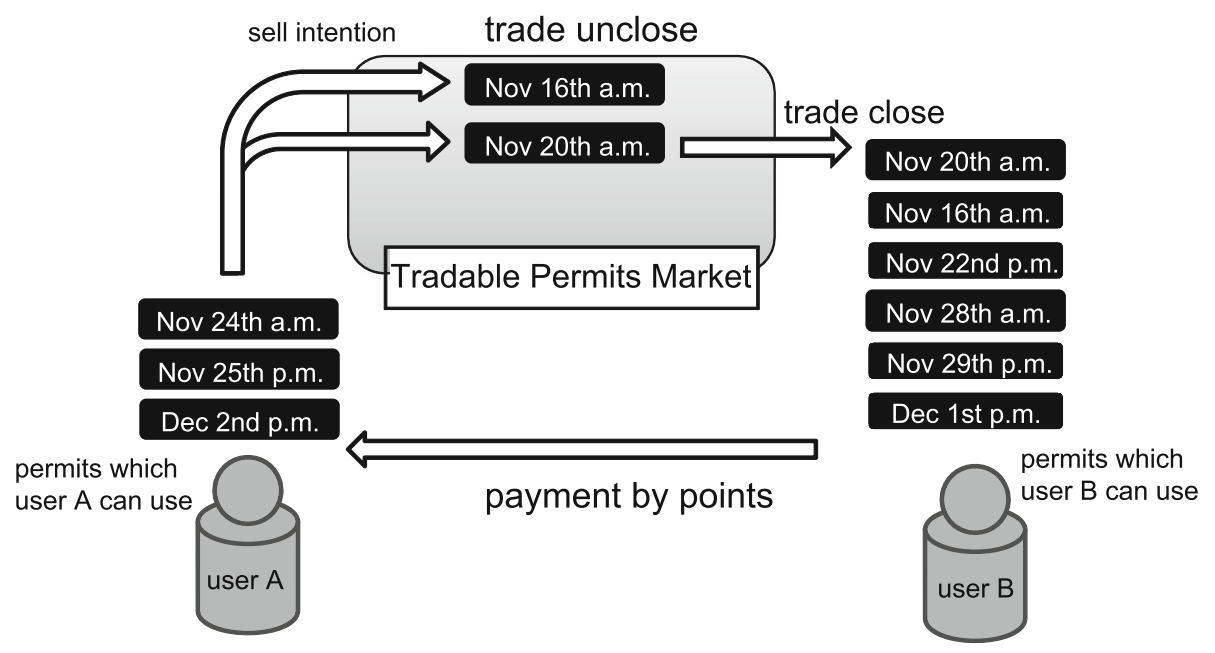

Fig. 3 The image of a double auction system

achieving fairness. In the example of Fig. 3, the initial allocation of user A is \{Nov 16th a.m., Nov 20th a.m., Nov 24th a.m., Nov 25th p.m., Dec 2nd p.m.\}. Then, if users do not intend to use permits, they can offer them for sale. In the example of Fig. 3, user A offers the permits of Nov 16th a.m. and Nov 20th a.m. Users who want the permits can buy them in a tradable permit system and the permits are reallocated based on the outcome of the trade. For example, when user B wants the permit of Nov 20th a.m., he/she bids the permits in tradable permit market. And if he/she wins the auction, he/she gets the permit and pay the price to user A. In the double auction, auction mechanism is also the second price auction and the currency for trading is transportation eco-points. If no one buys the permits which are sold in the tradable permit market by the expiry date, then the permits are spoiled at the expiry date. In the example of Fig. 3, the permit of Nov 16th a.m. is spoiled. This is a phase for achieving efficient allocation. This pilot program implemented both single- 
auction and double-auction systems. This paper focuses on the user behavior in a double auction mainly.

\section{Data}

The data in this study was collected from the "Yokohama Mobility Design Survey 2008" using the system noted above. Table 1 shows the overview of the data. The surveillance period was from 10th Nov. to 24th Dec., lasting 44 days. The activity and trips of participants were recorded by GPS mobile phone and web diary in detail. The number of participants was 118, and only 19 people participated in pilot program of the bicyclesharing service. In this study, we focus on the data of these participants and double-auction period (19 respondents, 23 days). Although the sample size in pilot program is small, there is no study to implement the pilot program of transportation service auction and to observe the travel and transaction behavior for more than 1 month. From the observation and analysis, we can discover the problem of transportation service auction and the important factor that affect users' transaction behavior. The male-to-female ratio in this data is 5:4 and the ratio of people in their 20,30 , and $40 \mathrm{~s}$ is $2: 7: 1$.

The double auction took place from 14th Nov. to 2nd Dec. and single auction took place from 3rd Dec. to 24th Dec. The auction site is linked from each participant's web diary page. At this auction site, participants could buy or sell their permits freely by presenting their sales information and purchase intention. In these transactions, they used transportation eco-points as virtual money. In the double auction, all tradable permits were randomly allocated to all users. In the period of the double auction, the number of total capacity of permits is 114. Each participants had 5 or 6 permits initially. To trade their permits and transportation eco-points, each participants used a permit auction website that operated like eBay.

\section{Basic analysis}

\section{The results of the auction transaction and research question}

First of all, we show the behavioral patterns in the bicycle-sharing permit auction. In the single auction setting, there are two classes of users. One class is the users who buy permits in auction. The other class is the users who do not buy it. Figure 4 shows about $20 \%$ of users participated in the auction. On the other hand, there are four classes of users in the double auction setting. they are "sold the permits they had and purchased permits they did

Table 1 Overview of pilot program

\begin{tabular}{ll}
\hline $\begin{array}{l}\text { Surveillance period } \\
\text { Survey method }\end{array}$ & $\begin{array}{l}44 \text { days }(2008 / 11 / 10-2008 / 12 / 24) \\
\text { Probe Person Survey + Web diary }\end{array}$ \\
The number of participants & (Probe person survey) 118 people \\
& (Bicycle sharing pilot program) 19 people \\
Area & Yokohama metropolitan area \\
The number of total capacity of permits & 114 permits in double auction period \\
The number of total trips & 16042 trips \\
\hline
\end{tabular}




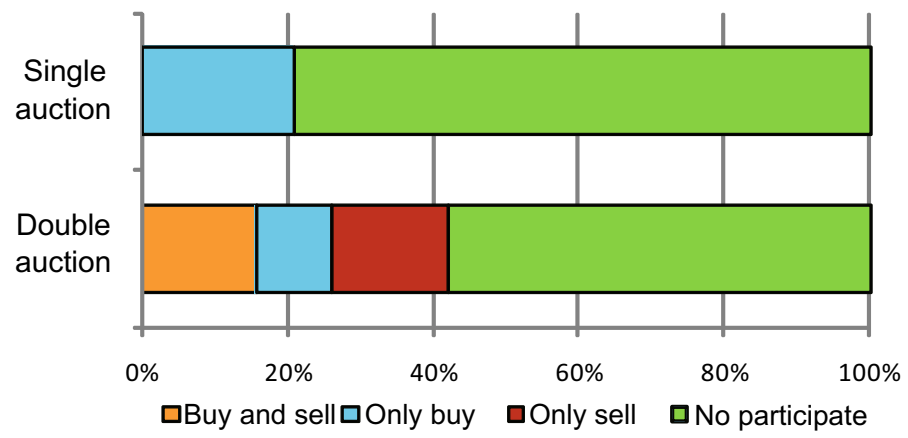

Fig. 4 Ratio of auction participation

not have", "only purchased permits they did not have", "only sold the permits they had", and "did not participate at all during the period". Figure 4 shows about $40 \%$ of users participated in the auction in any way and about $20 \%$ of users both bought and sold permits on the auction web site. In the surveillance period, there were 24 transactions in doubleauction setting and 11 transactions in single-auction setting. Only 5 users, whose user IDs were ym205, ym209, ym210, ym215, and ym219, made 25 transactions, making up about $70 \%$ of all transactions. This result indicates that a few users were active and most users are inactive in auction transactions of this pilot program.

In the single-auction setting, there were six biddings, which were all closed. Four permits were holiday permits and had execution prices of over 500 eco-points. There was no bidding-up in any bidding. On the other hand, there were 18 selling intents and 6 buying intents but closed transaction in only one in the double-auction setting. Sellers intended to sell their permits at over 100 eco-points, and some sellers differentiated permit prices, for example, by setting weekday permits at 100 points, Saturday permits at 300 points, and Sunday permits at 500 points. This result indicates that participants recognized that the value of bicycle-sharing permits depended on the characteristics of the permits. The closed transaction was for the permit for the morning on a holiday (24th Nov) and the execution price was 100 points. The buyer showed the buying intent of the permit in the auction site and the seller coupled with the request. The permits of remaining five buying intents expired because the users with the permits neither use nor sell them. This is the problem of mismatching for permit allocation; one cause of the problem is that the number of participants in the pilot program was small and the auction market was thin. Another reason was the difficulty of future decision-making under uncertainty about a user's future schedule. Judging from the above, we found that the bicycle-sharing auction mechanism could not achieve efficient allocation in practice, unlike in the case of the theoretical analysis, because of several realistic factors arising from the implementation of the pilot program.

\section{Transaction analysis focused on decision-making timing}

In this pilot program, all permits in the double-auction setting were randomly allocated to all participants. On the first day of pilot program, therefore, each participant has their own permits. The permits were valid on various days, with a maximum of 22 days and a minimum 4 days before permit expiry. 


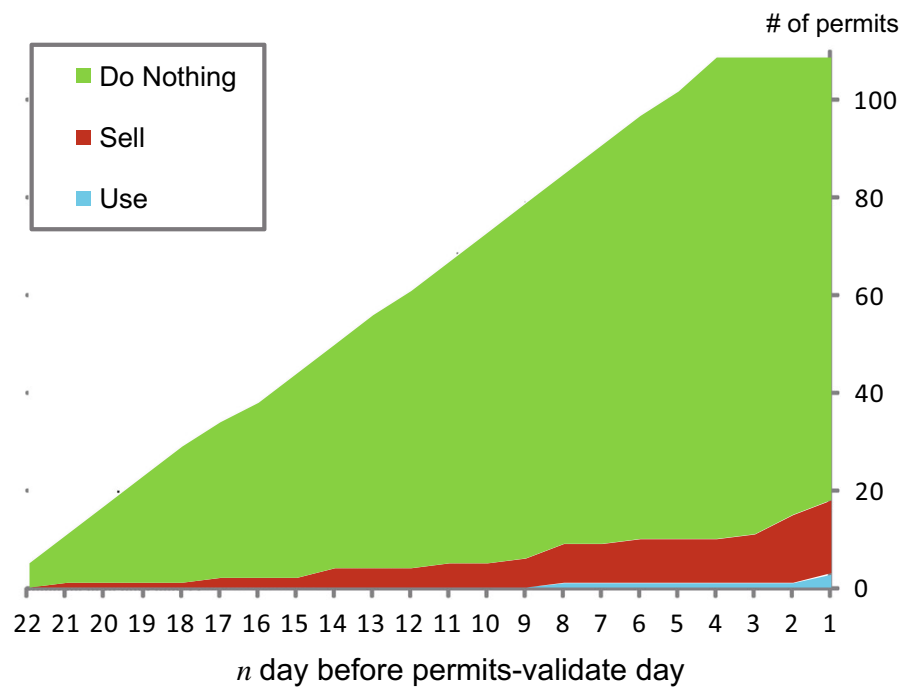

Fig. 5 Result of total decision-making of each day

Figure 5 shows when decisions were made about each permit. First of all, this figure shows that almost $80 \%$ of the permits were wasted because the participants neither intended to sell them nor use them. In the case of using permits, almost all participants made the decision on the day before permit expiry, and the earliest participant made their decision 8 days before. The ratio of permit selling also increased as the permit expiry approached. Figure 5 indicates that it was difficult for participants to make decisions about their permit until the deadline was near.

As an illustrative example, Figure 6 shows the transaction behaviors of the users with the IDs ym205 and ym210. ym205 (left) made a decision about their permit more than a week in advance. On the other hand, ym210 (right) booked for use or sold their permits
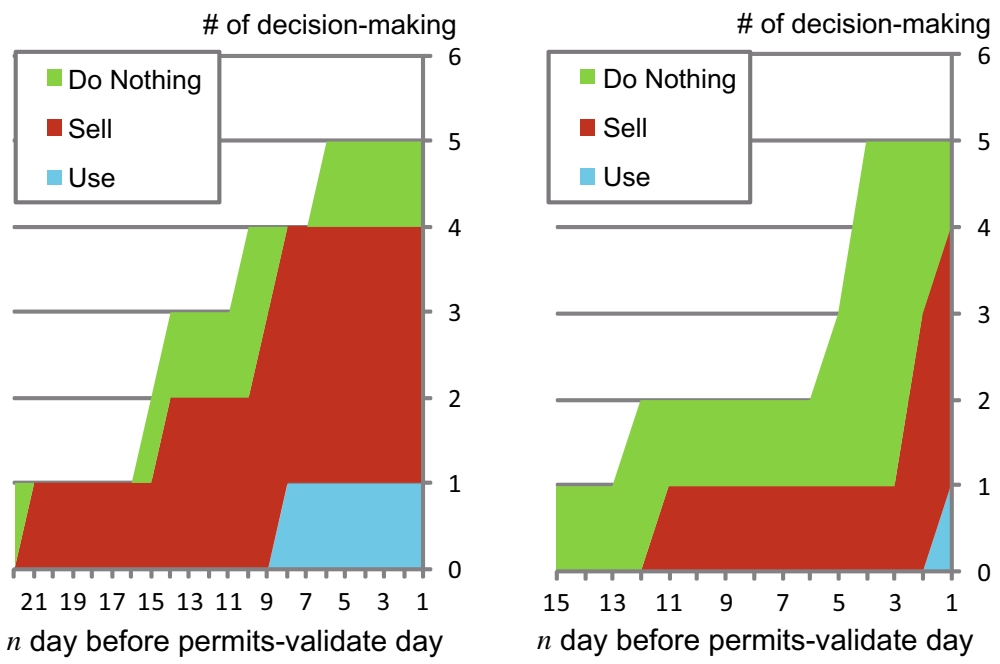

Fig. 6 The examples of decision-making timing. Left is user ID: ym205 and Right is user ID: ym210 
around the previous day. These results indicate that there is heterogeneity in both future schedule uncertainty and attitude toward bicycle-sharing permits, and that these effects are important to figure out for efficient allocation.

\section{Analysis of the time of active decision-making}

Now, we analyze the time of active decision-making to clarify the factors affecting future decision-making, such as reservation behavior and transaction behavior. Figure 7 shows the time of active decision-making in a tradable permit auction and there are two peaks: corresponding to lunch hour and evening. From probe person data, the places where the participants made their decisions were their homes (13 times) and work places ( 5 times). In the case of work place, the time of active decision-making was noon (4 times) and 14:00 (once). And this suggests that people actively decided what to do with their permits in their free time. This result is intuitive and indicates that active decision-making about tradable permits needs disposable time, which is the time remaining after the mandatory activity time is subtracted from the daytime.

We hypothesize that disposable time affects future decision-making. Probe person data show the location of each individual and sojourn time at each stop, but they cannot show activity in detail. Therefore, we define days upon which users stay at home for over 10 hours as free-time days. Figure 8 shows the relationship between the day-to-day decisionmaking and number of free-time days; it indicates that a large number of free-time days decreases the number of decisions to "do nothing" and increase the number of decisions to "use" and "sell". This result suggests that the availability of free time affected decisionmaking about future schedules and future travel behavior.

Figure 9 shows the relationship between decision-making about permits and the cumulative number of MM area visits. When the cumulative number of MM area visits is 0 , the ratios of "do nothing" and "sell" to "use" are high. This tendency indicates that participants with low numbers of MM area visits tended not to use their permits and think of trading their permits to other users from the very beginning. On the other hand, the participants whose number of MM area visits was more than 5 decided to "use", indicating that the number of $\mathrm{MM}$ area visits affected the use of permits.

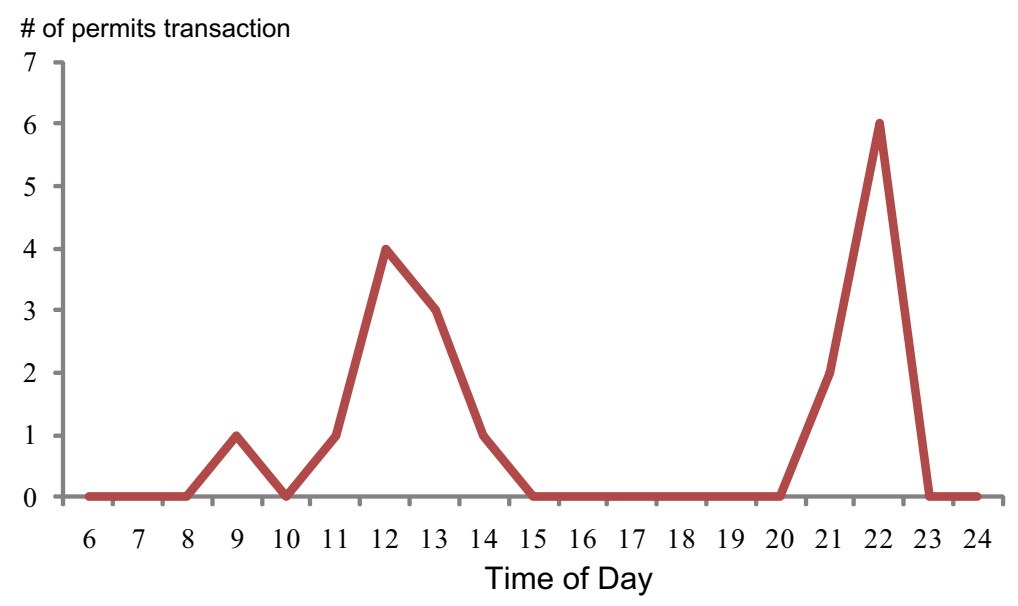

Fig. 7 Time of day of auction transaction 


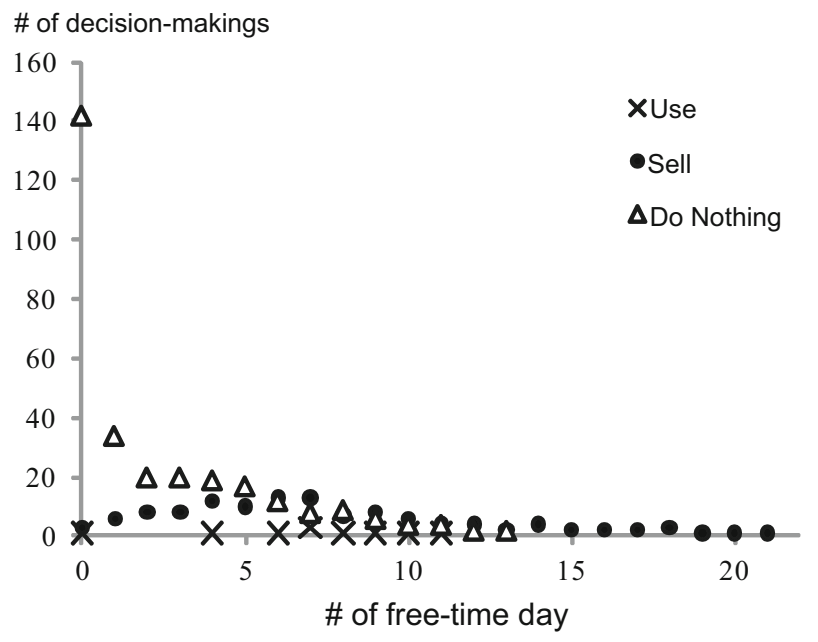

Fig. 8 The relationship between the number of free-time days and decision-making

Fig. 9 The relationship between the number of MM area visits and decision-making

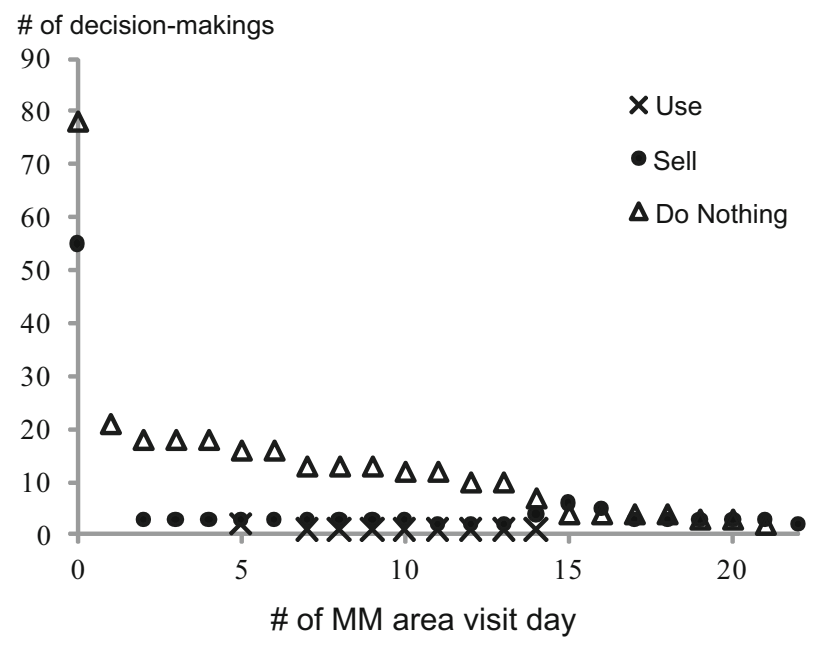

Figures 8 and 9 show that the decision-making of each participant depended not only on static elements such as the values of the permits and the socio-demographic characteristics but also dynamic elements such as day-to-day behavior and remaining days until permit expiry.

\section{Analysis considering activity patterns}

Now, we analyze the relationship between auction transactions and MM area visits. Since we implemented the tradable permit system of bicycle-sharing in the MM area in this pilot program, the users who had no scheduled visits to the MM area or could not visit the MM area because of time pressures tended to have an increased intention of selling permits. Figure 10 shows the relationship between transaction behavior and MM visits without 


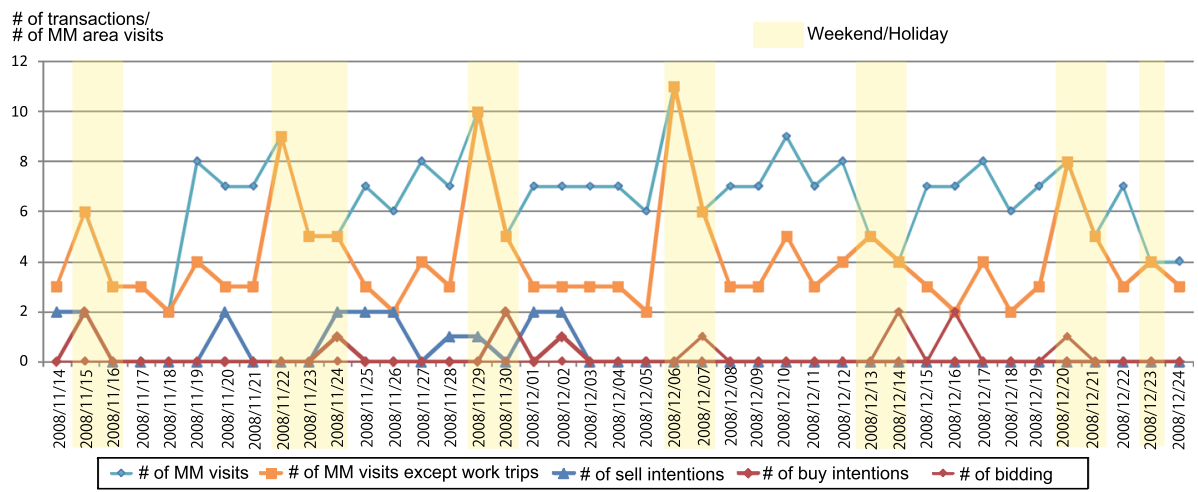

Fig. 10 Time series of auction transactions and MM area visits

work purpose. The days marked in yellow are weekends and holidays. The figure shows that the intention to sell permits increased on weekdays, and the intention of purchasing permits increased on weekends and holidays. The result shows that the activity patterns affect auction transactions.

Figure 11 shows the number of MM visits and the number of auction transactions per day. On holiday, the number of MM visits was over twice its weekday value, and there were many opportunities for bicycle-sharing on holidays. There is a slightly greater intention to sell permits on weekdays than on holidays; on the other hand, there is a significant intention to purchase permits oh holidays.

The average asking price of weekday permits in the double auction was 100 points, whereas the asking price of weekend permits was 240 points. On the other hand, the average price from a buyer was 100 points on both weekdays and weekends. As we set the threshold of the bidding price to 500 points in a single auction, the price of all permits that users purchased was 500 points.

The number of purchase intentions per day in the double-auction setting was 0.083 on weekdays and 0.714 on holidays. The number of biddings per day in the single-auction setting was 0.133 on weekdays and 0.571 on holidays. Though the tendency on weekdays is different from that on holidays, the type of auction did not affect demand for the permits

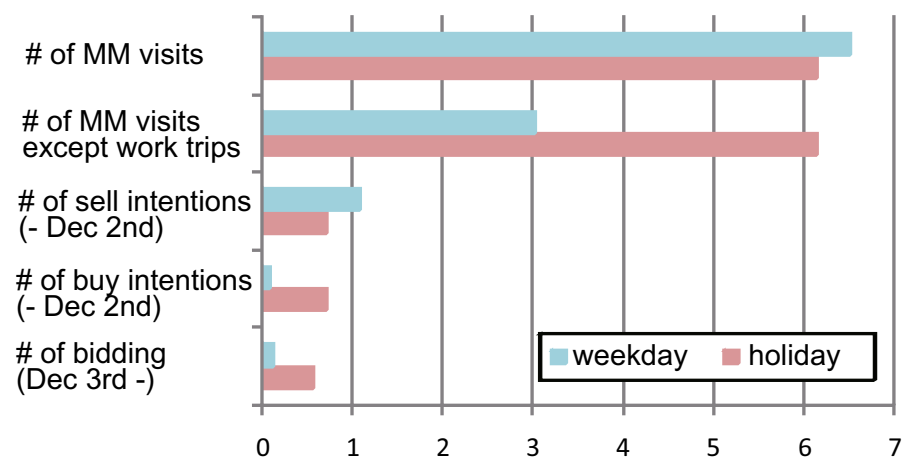

Fig. 11 The difference in activities between weekdays and weekends 
because t-test reports no significant difference between the average demand of single auction and that of the double auction.

\section{Analysis considering user home location and mode of transport}

Next, we analyze the relationship between the number of MM area visits and the locations of par residences. Figure 12 shows that the number of MM visits decreased with the increasing distance from home, both for all-purpose visits and non-work-related visits.

In a similar way, Figure 13 shows that the relationship among auction transactions, bicycle use, and participants' place of residence. It indicates that (1) neighborhood users used the bicycle-sharing system frequently and tended to sell the permits when they were not needed; (2) users who lived a moderate distance from the MM area tended to keep their permits and use bicycle-sharing most frequently out of the 3 groups; (3) users who lived a

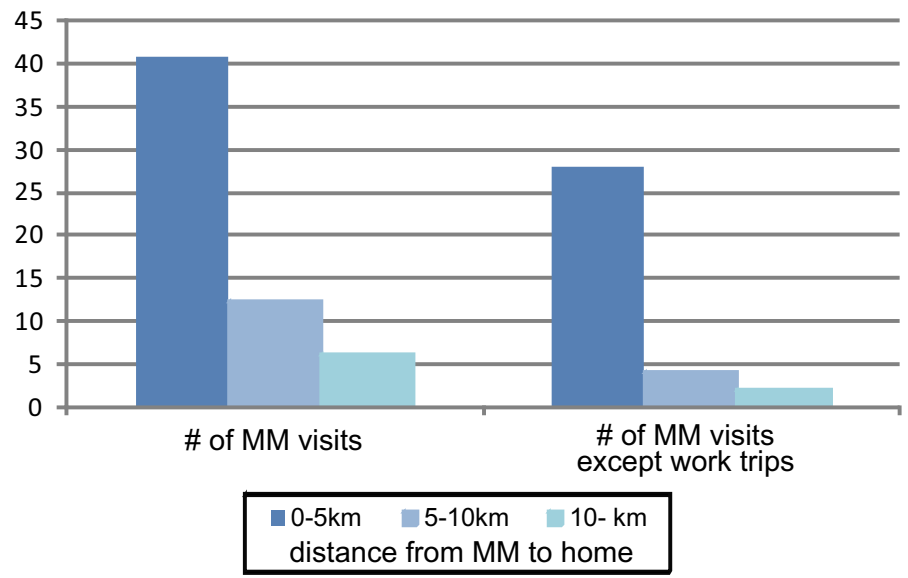

Fig. 12 The relationship between MM area visits and distance from home

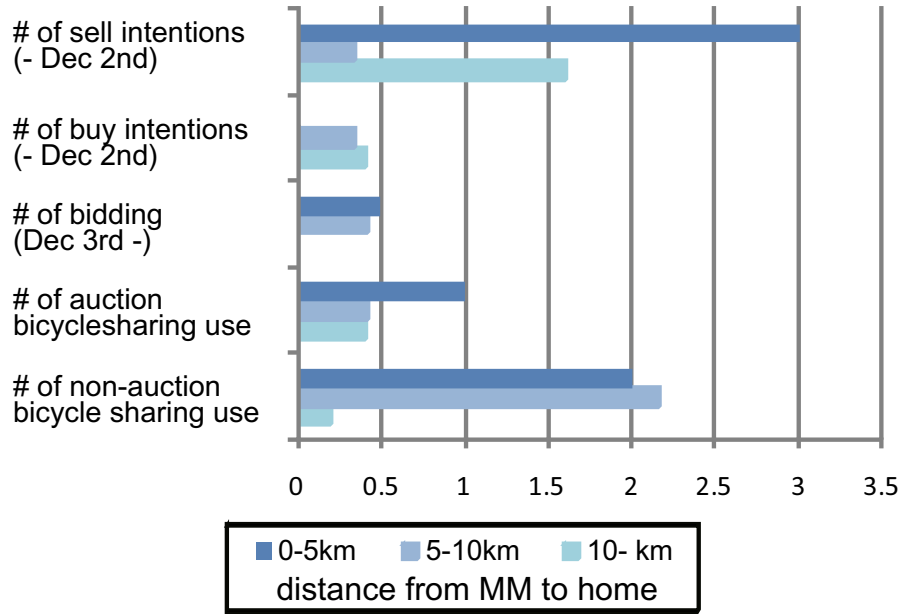

Fig. 13 The relationship between auction transaction and distance from home 
long distance from the MM area rarely used bicycle-sharing and tended to sell their permits.

We examined user tendency for bicycle-sharing on the basis of these results. As the neighborhood users lived near the MM area and had many opportunities to use bicyclesharing but also had the option of walking or using private bicycles for visiting the MM area, bicycle-sharing was one of several options for them. As middle-distance users visited the MM area more frequently than long-distance users and the MM area was too far to go by private bicycle, they could benefit from bicycle-sharing. Long-distance users did not use bicycle-sharing frequently because they did not visit the MM area frequently. From the above discussion, we think that middle-distance users attached more value to bicycle-sharing.

This discussion can be supported by following fact. Figure 14 shows the shares of various modes of transportation to the MM area sorted by distance from home. It does not include neighborhood users because their home is within MM area. For both weekdays and weekends, public transportation such as trains and buses were used by the largest share of middle- and long-distance users. This indicates that middle- and long-distance users who visited the MM area by public transport lacked mobility in the MM area and had restriction to travel freely according to their needs, so bicycle-sharking could generate latent travel demand among these people.

\section{Dynamic discrete choice modeling for choice dynamics}

\section{The formulation of the dynamic discrete choice model}

In this section, we formulate the dynamic discrete choice model for describing choice dynamics. This study focuses on the transaction behavior of user own tradable permits. The objective of our model and analysis is to clarify the contributing factors to the choice result and choice timing.

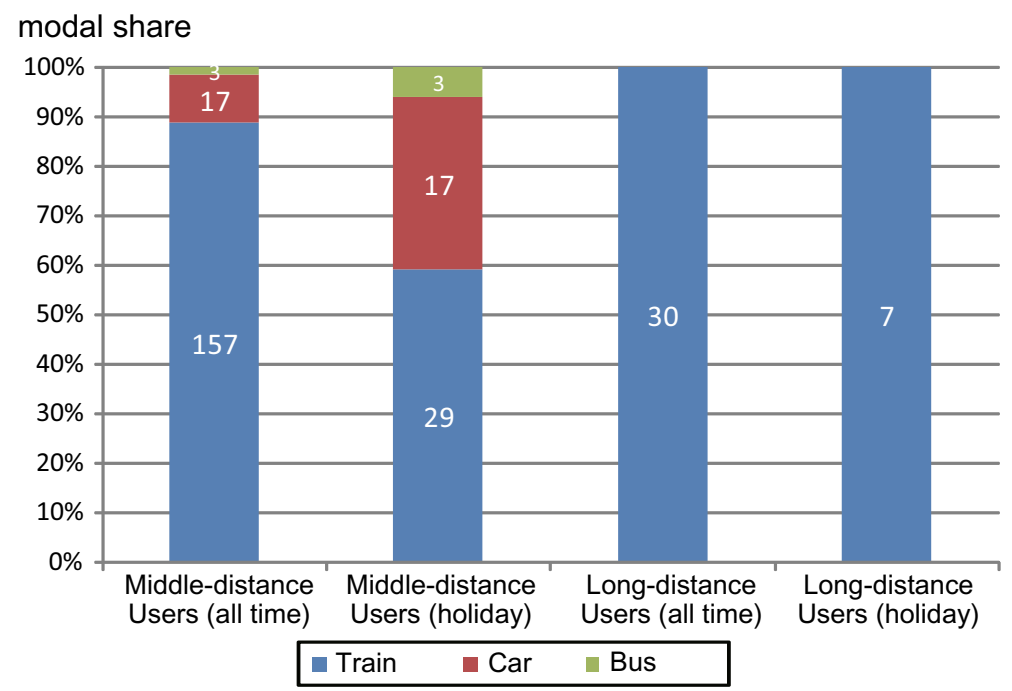

Fig. 14 The mode share sorted by distance between home and the MM area 
We index individuals by $i$. Time is discrete and indexed by $t$. Each individual $i$ can use a transport service only with a tradable permit (indexed by $r$ ). All permits are allocated to individuals at random. Each permit has a valid time slot for accessing the transport service and the permit is invalid outside of the valid time slot. In this situation, the choice set of each individual is $J=\{$ use, sell, donothing $\}$. We notate the choice set $J=\{1,2,3\}$. We assume that each individual $i$ makes a decision about their own permits $r$ every day between the day permits are distributed to the day until when their validity expires. The period in which individual $i$ makes a decision about his/her permit $r$ is $t=\left\{1,2, \ldots, T_{i r}\right\}$.

The state of the world at period $t$ for individual $i$ is determined by the state vectors $\boldsymbol{s}_{i t}$ and the choice result $a_{i t}$. The choice result $a_{i t}$ indicates the choice of the individual $i$ at time period $t$. On the other hand, the state vector $s_{i t}$ is the group of variables which indicate the state of the individual $i$. In particular, the state vector is consist of $y_{i t}, \varepsilon_{i t}, r_{i t}, c_{i t}, m_{i t}, a n d b_{i t}$. $y_{i t}$ denotes the state of the permit of the individual $i$ before the choice of time period $t$. $\varepsilon_{i t}$ denotes the unobserved error term. The set of state variable $y_{i t}$ is the same as $J$ and the set of state variable $a_{i t}$ is also the same as $J$. As the state variables which describe the state of the individual $i, r_{i t}$ is the remaining number of permit-valid days at time $t, c_{i t}$ is the cumulative number of days on which the individual $i$ has large disposable time, which is the time remaining after the mandatory activity time is subtracted from the daytime, $m_{i t}$ is the cumulative number of days on which the individual $i$ visits the area where the transportation service is implemented, and $b_{i t}$ is the cumulative number of days on which the individual $i$ uses their bicycle. Hence, $\boldsymbol{s}_{i t}=\left(y_{i t}, \varepsilon_{i t}, r_{i t}, c_{i t}, m_{i t}, b_{i t}\right)$. The choice set $J$ can also change depending on the choice result of the day before. Once the individual $i$ decides to use or sell the permit $r$, the choice set after the day is limited to the choice result. Hence, if the individual $i$ postpones their decision about the permit, the individual will face the choice situation on the next day. This relationship can be represented by

$$
\begin{aligned}
& J_{i, t+1}=\{1,2,3\} \quad \text { if } a_{i t}=3 \\
& J_{i, t+1}=\left\{j_{i t}\right\} \quad \text { otherwise. }
\end{aligned}
$$

The relationship between the state variable $y_{i t}$ and the choice result $a_{i t}$ is shown by Fig. 15 .

Individuals' preferences over possible sequences of states of the world can be represented by a utility function $\sum_{j=t}^{T} \beta_{i}^{j} U\left(a_{i, t+j}, \boldsymbol{s}_{i, t+j}\right)$, where $\beta \in(0,1)$ is the discount factor and $U\left(a_{i t}, s_{i t}\right)$ is the current utility function. As each individual faces uncertainty of future state variables, their belief in particular future state variables can be represented by the Markov transition distribution function $F\left(s_{i, t+1} \mid a_{i t}, s_{i t}\right)$. In every period $t$, the individual observes the vector of state variables $\boldsymbol{s}_{i t}$ and chooses their action $a_{i t} \in J$ to maximize their expected utility

$$
E\left(\sum_{j=0}^{T-t} \beta_{i}^{j} U\left(a_{i, t+j}, s_{i, t+j} \mid a_{i t}, s_{i t}\right)\right) .
$$

This is the individual's dynamic programming (DP) problem. Let $V\left(s_{i t}\right)$ be the value function of the DP problem. By Bellman's principle of optimality, the value function can be obtained using the recursive expression:

$$
V\left(s_{i t}\right)=\max _{a \in A}\left\{U\left(a, s_{i t}\right)+\beta_{i} \int V\left(s_{i, t+1}\right) d F\left(s_{i, t+1} \mid a, s_{i t}\right)\right\} .
$$

For simplicity, we define that $z_{i t}=\left(r_{i t}, c_{i t}, m_{i t}, b_{i t}\right)$. Then we can distinguish the subsets of the state variable $s_{i t}=\left(y_{i t}, \varepsilon_{i t}, z_{i t}\right)$. We assume that the error term follows an independent 


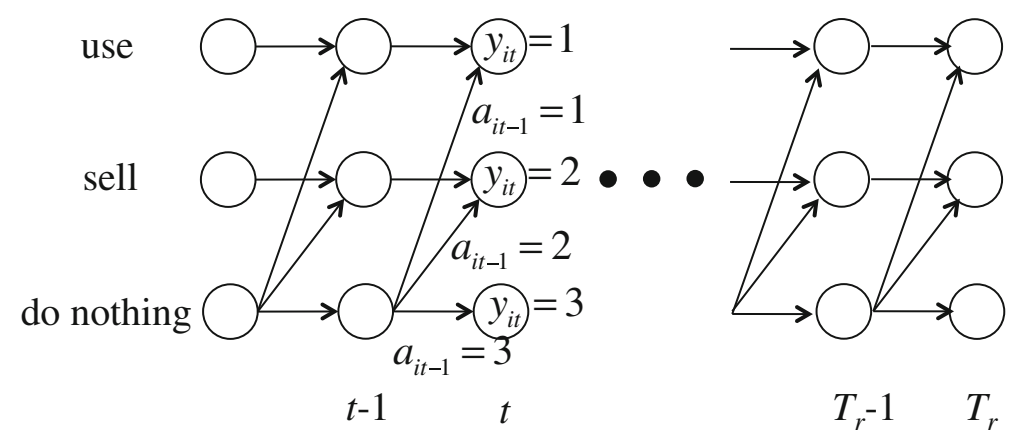

Fig. 15 The relationship between the state variable $y_{i t}$ and choice result $a_{i t}$

and identically distributed (i.i.d.) extreme value distribution. When $u\left(a_{i t}, y_{i t}, z_{i t}\right)$ is the utility function of each alternative $a_{i t}$, the value function $v\left(a_{i t}, y_{i t}, z_{i t}\right)$ of each alternative $a_{i t}$ is as below:

$$
v\left(a_{i t}, y_{i t}, z_{i t}\right)=u\left(a_{i t}, y_{i t}, z_{i t}\right)+\beta \sum_{y, z} \bar{V}\left(y_{i, t+1}, z_{i, t+1}\right) f_{y, z}\left(y_{i, t+1}, z_{i, t+1} \mid a_{i t}, y_{i t}, z_{i t}\right)+\varepsilon_{i t},
$$

where $\bar{V}\left(y_{i t}, z_{i t}\right) \equiv \int V\left(y_{i t}, z_{i t}, \varepsilon_{i t}\right) d G_{\varepsilon}\left(\varepsilon_{i t}\right)$.

Using the value function of each alternative, the choice probability of the dynamic discrete choice model follows the same form as the static discrete choice model:

$$
P\left(a_{i t} \mid y_{i t}, z_{i t}, \theta\right)=\frac{\exp \left(v\left(a_{i t}, y_{i t}, z_{i t}\right)\right)}{\sum_{J} \exp \left(v\left(a_{i t}^{\prime}, y_{i t}, z_{i t}\right)\right)} .
$$

In addition, we assume conditional independence between the error and transition distributions:

$$
\begin{aligned}
P\left(\varepsilon_{i, t+1}, y_{i, t+1}, z_{i, t+1} \mid \varepsilon_{i t}, y_{i t}, z_{i t}\right)= & g\left(\varepsilon_{i, t+1} \mid x_{i, t+1}\right) \cdot f_{y}\left(y_{i, t+1} \mid a_{i t}, y_{i t}\right) . \\
& f_{r}\left(r_{i, t+1} \mid r_{i t}\right) \cdot f_{c}\left(c_{i, t+1} \mid c_{i t}\right) \cdot f_{m}\left(m_{i, t+1} \mid m_{i t}\right) \cdot f_{b}\left(b_{i, t+1} \mid b_{i t}\right) .
\end{aligned}
$$

By the conditional independence between the error term and transition probability, we can identify the solution of DP problem as the expectation of the value function over the error distribution $\bar{V}\left(x_{i t}\right) \equiv \int V\left(x_{i t}, \varepsilon_{i t}\right) d G_{\varepsilon}\left(\varepsilon_{i t}\right)$, as described above.

As state variables in this study, we define variables that do not change for time $t$ by $x_{i}$ and variables that shift for time $t$ by $r_{i t}, c_{i t}, m_{i t}, b_{i t}$. We assume the Markov transition function of these state variables as given below:

$$
\begin{gathered}
r_{i, t+1}=r_{i t}-1 \\
c_{i, t+1}=f_{c}\left(c_{i t}\right) \\
m_{i, t+1}=f_{m}\left(m_{i t}\right)
\end{gathered}
$$




$$
\begin{gathered}
b_{i, t+1}=f_{b}\left(b_{i t}\right) \\
r_{i 1}=T_{i j}, c_{i 1}=0, m_{i 1}=0, b_{i 1}=0,
\end{gathered}
$$

In this study, we assume the structure of the transition function $f_{c}\left(c_{i t}\right), f_{m}\left(m_{i t}\right)$, and $f_{b}\left(b_{i t}\right)$ as below:

$$
\begin{aligned}
f_{c}\left(c_{i t}\right) & \equiv \frac{\exp \left(V_{c}\right)}{1+\exp \left(V_{c}\right)}+c_{i t} \\
f_{m}\left(m_{i t}\right) & \equiv \frac{\exp \left(V_{m}\right)}{1+\exp \left(V_{m}\right)}+m_{i t} \\
f_{b}\left(b_{i t}\right) & \equiv \frac{\exp \left(V_{b}\right)}{1+\exp \left(V_{b}\right)}+b_{i t},
\end{aligned}
$$

where $V_{c}, V_{m}, V_{b}$ denote the observed utility terms of each behavior. These equations indicates whether the individual $i$ chooses each behavior at time $t$, as well as the total number of days of each behavior. Whether the individual $i$ chooses each behavior at time $t$ can be represented by a binary logit model.

\section{The setting of utility function}

Then, we estimate the parameters of value functions and transition functions from observed data. Let $\theta$ be the parameters of utility functions. In accord with above analysis, we set the utility function of each alternative.

$$
\begin{gathered}
u_{1, t}=\theta_{\text {holiday }_{\text {holiday }}}+\theta_{\text {dist }} \log \left(x_{\text {dist }_{i}}\right)+\theta_{m m} m_{i t} \\
u_{2, t}=\theta_{\text {weekday }} x_{\text {weekday }_{i}}+\theta_{\text {am }} x_{\text {am }}+\theta_{\text {disptime }} c_{i t}+\theta_{\text {bicycle }} b_{i t} \\
u_{3, t}=\theta_{\text {sch }} \log \left(r_{i t}+1\right),
\end{gathered}
$$

where $x_{\text {holiday }_{i}}$ is the dummy variable of whether the day of the permit-validity is a holiday, $x_{\text {weekday }_{i}}$ is the dummy variable of whether the day of the permit-validity is a weekday, $x_{\text {dist }_{i}}$ is the distance $(\mathrm{km})$ from the participant's home to the MM area and $x_{a m_{i}}$ is the dummy variable of whether the time of the permit-validity is in the morning. These variables are constant with regard to temporal transitions. The state variables $m_{i t}, c_{i t}, m_{i t}$, and $r_{i t}$ are the variables that shift for time $t$ and are defined by Eqs. (7), (8), (9) and (10).

Next, we assume that each individual has his/her discount factor of future utility. The reason for different discount factors is that the discount factor is affected by individual attributes. Thus, we model the individual discount factor $\beta_{i}$ as a logistic function as

$$
\beta_{i}=\frac{\exp \left(\theta_{h m} x_{h m_{i}}+\theta_{40} x_{f_{\text {orty }}}\right)}{1+\exp \left(\theta_{h m} x_{h m_{i}}+\theta_{40} x_{f_{\text {orty }}}\right)},
$$

where $x_{h m_{i}}$ is the dummy variable for a full-time homemaker and $x_{f o r t y_{i}}$ is the dummy variable for someone in their $40 \mathrm{~s}$.

We set the Markov transition probability of the state variables as the binary logit model given below: 


$$
\begin{gathered}
u_{c}=\theta_{\text {holiday }} x_{\text {holiday }_{i t}}+\theta_{\text {worker }} x_{\text {worker }_{i}}+A S C_{c} \\
u_{m}=\theta_{\text {homeMM }} x_{\text {homeMM }_{i}}+\theta_{\text {officeMM }_{\text {officeMM }}}+A S C_{m} \\
u_{b}=\theta_{\text {holiday }} x_{\text {holiday }_{i t}}+\theta_{\text {hm }} x_{h m_{i}}+A S C_{b} \\
P\left(c_{i, t+1}=c_{i t}+1\right)=\frac{\exp \left(u_{c}\right)}{1+\exp \left(u_{c}\right)}, P\left(c_{i, t+1}=c_{i t}\right)=\frac{1}{1+\exp \left(u_{c}\right)} \\
P\left(m_{i, t+1}=m_{i t}+1\right)=\frac{\exp \left(u_{m}\right)}{1+\exp \left(u_{m}\right)}, P\left(m_{i, t+1}=m_{i t}\right)=\frac{1}{1+\exp \left(u_{m}\right)} \\
P\left(b_{i, t+1}=b_{i t}+1\right)=\frac{\exp \left(u_{b}\right)}{1+\exp \left(u_{b}\right)}, P\left(b_{i, t+1}=b_{i t}\right)=\frac{1}{1+\exp \left(u_{b}\right)},
\end{gathered}
$$

where $x_{\text {holiday }}$ is the dummy variable for whether the day $t$ is holiday for the individual $i$, $x_{\text {worker }_{i}}$ is the dummy variable for being a full-time worker, $x_{\text {homeM }_{i}}$ is the dummy variable for whether the individual $i$ 's home is in the MM area, $x_{o f f i c e} M_{i}$ is the dummy variable for whether the individual $i$ 's office is in the MM area and each ASC is an alternative specific constant. The initial values of state variables are $m_{i 0}=0, b_{i 0}=0, c_{i 0}=0$.

As we assume that the choice set can be limited by Eq. (1) and the error term follows i.i.d. extreme value distribution, the value function of each alternative at time $t$ can be written as

$$
\begin{gathered}
v_{1, t}=u_{1, t}+\beta_{i} v_{1, t+1} \\
v_{2, t}=u_{2, t}+\beta_{i} v_{2, t+1} \\
v_{3, t}=u_{3, t}+\beta_{i} \log \left(\exp \left(v_{1, t+1}\right)+\exp \left(v_{2, t+1}\right)+\exp \left(v_{3, t+1}\right)\right),
\end{gathered}
$$

because the expectation of value function of alternative 3 is the log-sum variable of the value functions at time $t+1$. To estimate the parameters, the value functions at each time can be computed backward from last time $T_{i r}$.

\section{Estimation method}

Let $\theta=\left(\theta_{u}, \theta_{f}\right)$ be the vector of structural parameters. The parameters of the value function are $\theta_{u}$ and the parameters of the transition function are $\theta_{f}$. To estimate $\theta$, we define the log likelihood function of individual $i$ by

$$
l_{i}(\theta)=\log \operatorname{Pr}\left\{a_{i t}, y_{i t}, z_{i t} ; t=1,2, \ldots, T_{i} \mid \theta\right\} .
$$

As we assume conditional independence between the error and transition distributions, we can split the probability function, $a_{i t}$ and the transition function, $x_{i t}$ :

$$
\operatorname{Pr}\left(a_{i t}, y_{i t} \mid a_{i, t-1}, y_{i, t-1}, z_{i, t-1}\right)=P\left(a_{i t} \mid y_{i t}, z_{i t}\right) f_{z}\left(z_{i t} \mid z_{i, t-1}\right) .
$$

Using these relationships, we can rewrite the log likelihood function of the individual $i$ as 


$$
\begin{aligned}
l_{i}(\theta)= & \sum_{t=1}^{T_{i r}} \delta_{a_{i t}} \cdot \log P\left(a_{i t} \mid y_{i t}, z_{i t}, \theta_{u}\right)+\sum_{t=1}^{T_{i r}-1} \delta_{z_{i, t+1}} \cdot \log f_{z}\left(z_{i, t+1} \mid a_{i t}, z_{i t}, \theta_{f}\right) \\
& +\delta_{z_{i 1}} \cdot \log \operatorname{Pr}\left(z_{i 1}\right)
\end{aligned}
$$

where $P(\cdot)$ is the choice probability at time $t, f_{z}(\cdot)$ is the transition probability of state variables, and $\delta$. is the Kronecker delta, which equals 1 when the individual $i$ choices and equal 0 otherwise. As Eq. (6) assumes conditional independence between the choice and transition probabilities, we can maximize each log likelihood function independently. Therefore, the $\log$ likelihood function for estimating parameters $\theta$ can be represented by

$$
\begin{aligned}
L_{i}(\theta)= & \sum_{i} \sum_{t=1}^{T_{i r}} \delta_{a_{i t}} \cdot \log P\left(a_{i t} \mid y_{i t}, z_{i t}, \theta_{u}\right)+\sum_{i} \sum_{t=1}^{T_{i r}-1} \delta_{z_{i, t+1}} \cdot \log f_{z}\left(z_{i, t+1} \mid a_{i t}, z_{i t}, \theta_{f}\right) \\
& +\sum_{i} \delta_{z_{i 1}} \cdot \log \operatorname{Pr}\left(z_{i 1}\right) .
\end{aligned}
$$

To estimate the parameters $\theta$ by the maximum likelihood estimation method, we only have to maximize the log likelihood function and obtain the parameters $\theta$.

\section{Comparison models}

To evaluate the effectiveness of our proposed model, we compare the dynamic discrete choice model with two static discrete choice model. The first static discrete choice model is the typical multinomial logit model, which does not include the dynamic factors. Because this model does not include the state variables that shift as the day goes on, the choice probability of each alternative is constant, regardless of the remaining days of permit-valid day.

The second static model has the structure as the first, but the state variables shift as the day goes on. Therefore, the dynamic model and the second static model have same utility function. However, the second static model does not consider the future utility under uncertainty, as does the value function. The parameters of these two static model can be estimated by a maximum likelihood estimation method.

\section{The estimation result of the dynamic discrete choice model and discussion}

\section{Estimation results and discussion}

First, we show the estimation result of the transition model of state variables $c_{i t}, m_{i t}, b_{i t}$ in Table 2 . The transition probability of the state variables has a simple structure that uses the individual attributes and characteristics of the day only. However, the likelihood ratio of each model is sufficient. With regard to the cumulative number of free-days, office workers tend to have more free-days and participants have small disposable time on holidays. The location of the home and office greatly impact the number of visits to the MM area. Fulltime homemakers tended to use bicycles regularly, and participants tended to use bicycle on holidays. Using these estimation results for transition probability, we compute the state variables at time $t$ and compute the value function of the dynamic discrete choice model.

Table 3 shows the estimation result of the dynamic discrete choice model. Static behavior model 1 is the lowest adjusted likelihood ratio and static behavior model 2, which 
Table 2 The estimation result of transition probability

\begin{tabular}{|c|c|c|c|c|c|c|}
\hline \multirow[t]{2}{*}{ variables } & \multicolumn{2}{|c|}{ Free-time at home } & \multicolumn{2}{|l|}{ MM visit } & \multicolumn{2}{|c|}{ Bicycle use } \\
\hline & Estimate & $\mathrm{t}$-val & Estimate & $\mathrm{t}$-val & Estimate & $\mathrm{t}$-val \\
\hline Holiday dummy & -1.490 & -7.98 & - & - & 0.828 & 3.70 \\
\hline Full-time worker dummy & 2.126 & 10.19 & - & - & - & - \\
\hline$A S C_{c}$ & -1.181 & -6.47 & - & - & - & - \\
\hline Home at MM dummy & - & - & 2.888 & 8.46 & - & - \\
\hline Office at MM dummy & - & - & 3.094 & 14.10 & - & - \\
\hline$A S C_{m}$ & - & - & -2.008 & -13.99 & - & - \\
\hline Full-time homemaker dummy & - & - & - & - & 2.548 & 11.45 \\
\hline$A S C_{b}$ & - & - & - & - & -2.550 & -14.37 \\
\hline Observations & 730 & & 730 & & 730 & \\
\hline Initial log likelihood & -505.997 & & -505.997 & & -505.997 & \\
\hline Final log likelihood & -410.770 & & -301.159 & & -282.797 & \\
\hline Likelihood ratio $\left(\rho^{2}\right)$ & 0.188 & & 0.404 & & 0.441 & \\
\hline Adjusted likelihood ratio $\left(\bar{\rho}^{2}\right)$ & 0.182 & & 0.399 & & 0.435 & \\
\hline
\end{tabular}

uses the state variables, has a higher adjusted likelihood ratio than the first model. The dynamic behavior model has the highest adjusted likelihood ratio among these models and the value is 0.614 . This result indicates that the dynamic behavior model can express the sequential decision-making from the point of view of both the model structure of a dynamic discrete choice model and the variables that the model uses.

The estimated parameter indicates that the available value of permits is high when the day of the permit-validity is on a holiday and low when the distance from home to the MM area is large. The more frequently the individual visits the MM area, the more the utility increases. This is the rational result for using permits.

With regard to selling permits, the result shows that individuals wanted to sell their permits when the permit expiry was a weekday and the time slot of the permit was in the afternoon. The number of free-days increased the decision-making for selling. As the basic analysis shows, the number of free-day was the important factor for active decisionmaking. The parameter of the amount of bicycle usage is positive, meaning that individuals who have their own bicycles do not need to share.

The utility function for postponing decision-making is set to the log function of the remaining days, and means that the uncertainty of the day of permit-validity decreased as time passed. On the other hand, postponing of decision-making had an option value that did not impose a limitation of the future choice set. Therefore, the estimation result indicated that each individual compared the current utility to the option value and chose whether postponing decision-making or active decision-making.

\section{Sensitivity analysis}

\section{Reproducibility of the dynamic model}

We assume that the discount factor has heterogeneity for socio-demographic attributes. The estimation result indicates that older people and full-time homemakers tended to have 
Table 3 The comparison of transaction behavior models

\begin{tabular}{|c|c|c|c|c|c|c|}
\hline \multirow[t]{2}{*}{ Variables } & \multicolumn{2}{|c|}{ Static model 1} & \multicolumn{2}{|c|}{ Static model 2} & \multicolumn{2}{|c|}{ Dynamic model } \\
\hline & Estimate & $\mathrm{t}$-val. & Estimate & $\mathrm{t}$-val. & Estimate & $\mathrm{t}$-val. \\
\hline Holiday permit dummy (use) & 2.376 & 3.68 & 1.043 & 1.85 & 0.806 & 1.13 \\
\hline $\log$ (distance from home) (use) & -1.063 & -3.15 & -1.089 & -3.30 & -0.949 & -2.79 \\
\hline The number of MM visits (use) & - & - & 0.083 & 1.31 & 0.133 & 2.13 \\
\hline weekday permit dummy (sell) & 3.509 & 6.74 & 2.522 & 7.01 & 2.201 & 6.30 \\
\hline Morning permit dummy (sell) & -0.538 & -2.10 & -0.938 & -3.44 & -0.637 & -2.97 \\
\hline The number of bicycle use (sell) & - & - & -0.036 & -0.45 & 0.132 & 1.94 \\
\hline The number of free day (sell) & - & - & 0.170 & 4.73 & 0.127 & 4.10 \\
\hline Log(remaining day) (do nothing) & - & - & 1.503 & 10.25 & 0.950 & 6.30 \\
\hline ASC (do nothing) & 3.622 & 6.81 & - & - & - & - \\
\hline Full-time homemaker dummy & - & - & - & - & 3.05 & 3.27 \\
\hline 40's dummy & - & - & - & - & 2.83 & 2.86 \\
\hline Observations & 429 & & 429 & & 429 & \\
\hline Initial log likelihood & -471.31 & & -471.31 & & -471.31 & \\
\hline Final log likelihood & -240.88 & & -206.60 & & -172.06 & \\
\hline Likelihood ratio $\left(\rho^{2}\right)$ & 0.489 & & 0.561 & & 0.635 & \\
\hline Adjusted likelihood ratio $\left(\bar{\rho}^{2}\right)$ & 0.476 & & 0.544 & & 0.614 & \\
\hline
\end{tabular}

a larger discount factors than younger people and other occupations. This shows that older people and full-time homemakers estimated the high option value of postponing decisionmaking. We interpret the result as meaning that full-time homemakers had more flexible schedule than office workers; hence, they had the high option value. The reason for high discount factor of people in their 40s was that the tradable permit system of bicycle-sharing was unfamiliar to them so they tended to postpone their decision-making.

We confirm of the reproducibility of the dynamic model. Figure 16 shows the example of actual choice result and the reproduced choice probability sequence by the above model. The individual (user ID: ym205) decided to use the permit 8 days before in the left figure and the individual (user ID: ym215) decided to sell the permit 8 days before in the right figure. On the other hand, our model reproduced the choice probability sequence for "use", "sell" and "do nothing". Thought the choice timing is not completely correct, our model can capture the tendency of each user's decision-making.

\section{Policy simulation}

Now, we think of the case in which the permit value is higher than observed data. One policy simulation is to change the distance from a user's home to the MM area. To verify the effect of the distance from their home, we compute the choice probability sequence under a distance change within $2 \mathrm{~km}$. Figure 17 shows the choice probability in the observed setting by a solid line and the choice probability in the simulation setting by a dotted line. It is found from the result that a higher permit value makes a higher choice probability for using the permit. However, the choice timing in the temporal axis has the 


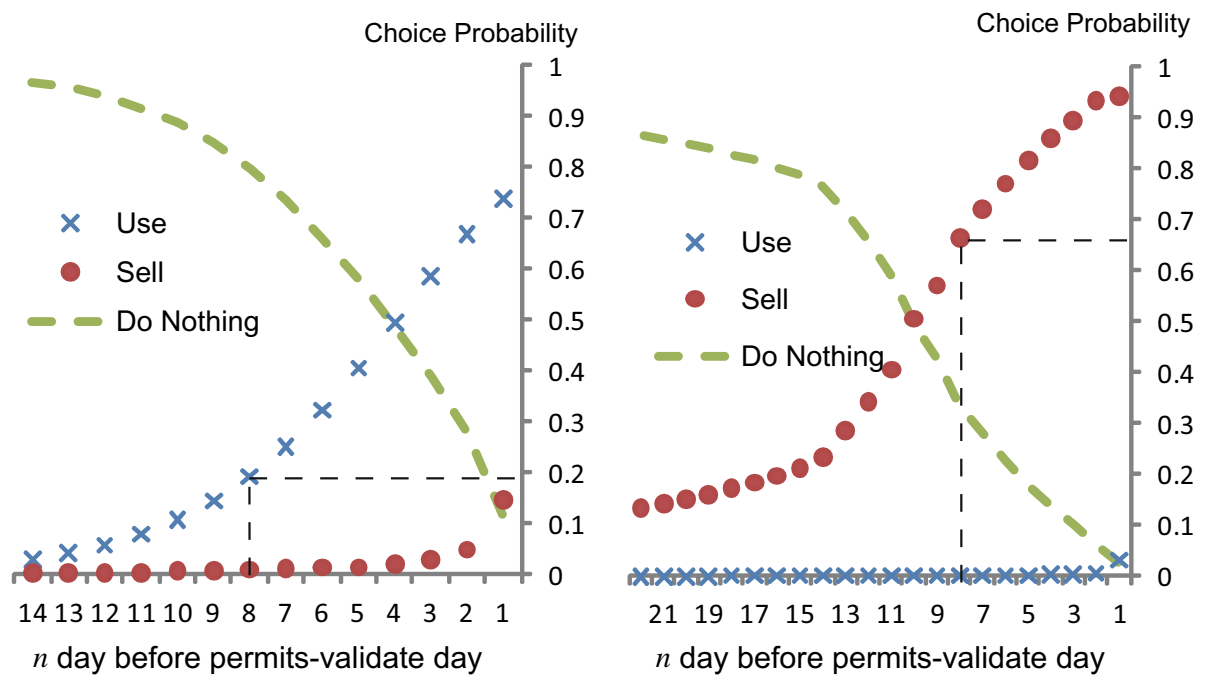

Fig. 16 The estimated choice probability sequence of each alternative. Left is user ID: ym205, permit expiry is 24th Nov. and right is user ID: ym215, permit expiry is 2nd Dec

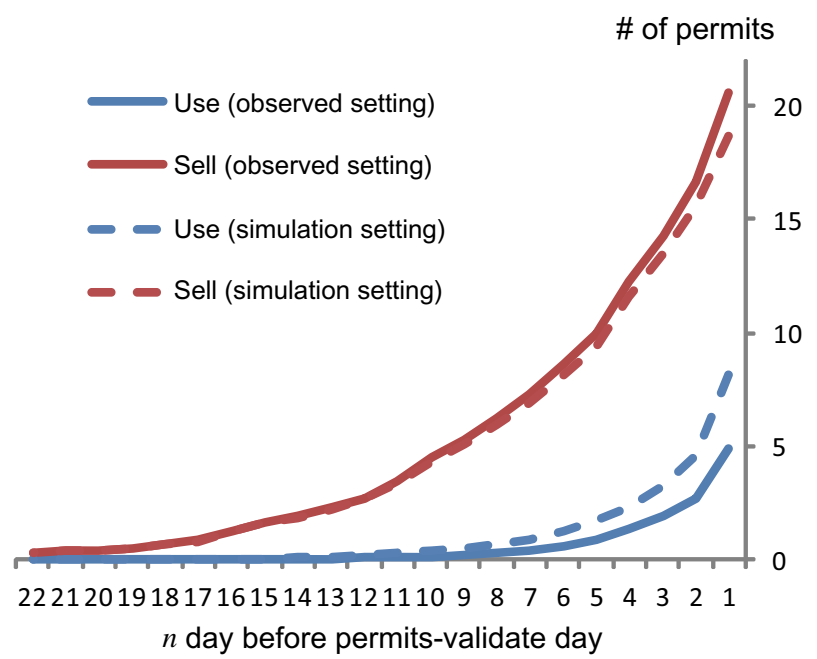

Fig. 17 The sensitive analysis for the high permit value case

same tendency as the observed setting. Hence, the permit value affected the final choice result but did not affect the choice timing.

Finally, we consider the case where the discount factor is lower than observed data. Figure 18 shows the result where the discount factor of all participants is $1 / 2$. Because the final utility term is the same as the observed data in this setting, the final choice result and choice probability are the same. However, the result indicates that participants made decisions earlier because the option value generated by postponing decision-making was low. 


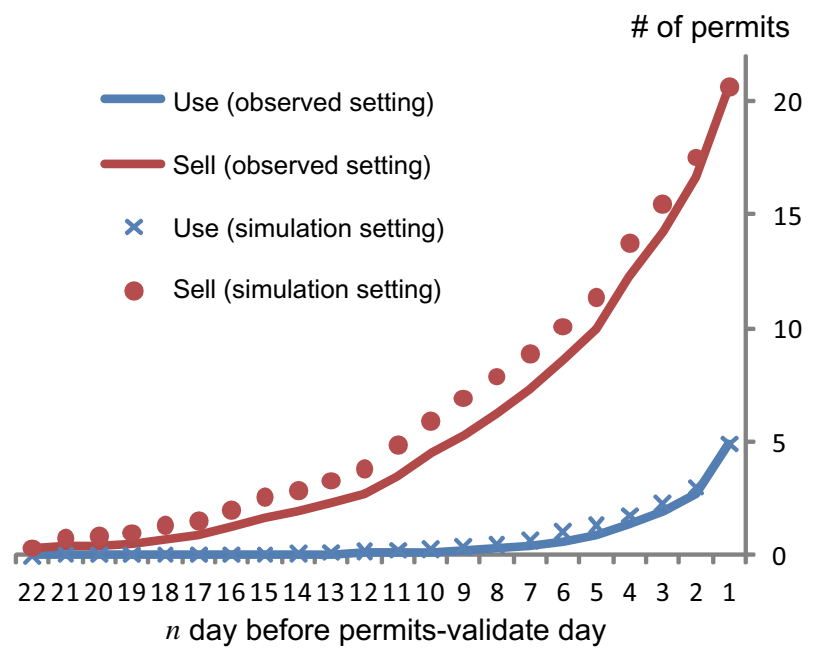

Fig. 18 The sensitive analysis in the case where the time discount factor is low

The implication from these results is that a policy that improves the permit value or increases population of participants cannot solve the problem that participants made decisions about their permits at the last minute. As many participants performed such an action, the double auction in the tradable permit system could not achieve the efficient allocation by participants' transactions only. This analysis and this pilot program indicate that efficient relocation of tradable permits need not only a market mechanism but also understanding participants' schedule under uncertainty.

\section{Conclusions}

In transportation research area, little attention has been paid to auction-based transportation services except tradable credit scheme or tradable permit system. Tradable credit scheme and tradable permit system were analyzed theoretically but there is no empirical study of these schemes. The novelty of this research is that we implemented a tradable permit system as a new bicycle-sharing system in Yokohama city. And we designed our pilot program inspired by experimental economics. The currency of pilot program is not real money but a "virtual money". However, it has the incentive compatible social pilot program by the induced value theory. In addition, we analyzed users' travel behavior and transaction behavior empirically and clarified the issue of transportation service auctions. Although the number of participants in this pilot program was not large and transactions were not very active, our data showed the complex relationship between travel behavior and transaction behavior. It is one of the interesting results of our pilot program. The other contribution of our empirical study is that postponement of decision-making under uncertainty, which have received insufficient attention in previous studies, has an impact on the decision-making timing.

Using behavior and transaction data from social pilot program, we estimated transition probability and transaction behavior model by dynamic discrete choice model. From the estimation results, we showed the relationship among postponement of decision-making, 
the number of free-time days, and the number of MM area visits. As this basic analysis, we modeled the sequential decision-making for permits by a dynamic discrete choice model and clarified the contributing factors that affected the decision-making timing using parameter estimation. The estimation results showed that the option value of postponing decision-making caused the transactions to occur at the last minute, and that this effect blocked the liquidity of the permits trade. In addition, we showed the heterogeneity of the time discount factor, which indicated that initial allocation was important for efficient allocation. Finally, the sensitivity analysis of the dynamic discrete choice model could simulate the sequence of choice probabilities. These simulations showed the relationship between each parameter and choice timing.

For future work, there are some issues in our empirical study. As the issues of our pilot program, the number of samples and the number of active users were too small; hence, our results are limited in terms of their general implications. We could only show the interesting fact finding at this time. We need to implement a larger pilot program as the way to approach this issue. In addition, it is necessary to validate tradable credit/permit scheme empirically for not only a bicycle-sharing service but also road network. To analyze user behavior under a complex system such as a tradable credit/permit scheme, additional empirical studies are needed. As the issues of our empirical analysis, our approach needs to be modified with two estimation steps for transition probabilities and the dynamic discrete choice model. To estimate consistent parameters, simultaneous estimation is needed. And the assumption of transition probabilities is simple. We need to readjust the assumption. To model the decision-timing under the uncertainty, it is useful to use dynamic discrete choice model. The model structure of dynamic discrete choice model and the parameter estimation are important for describing future decision-making.

Acknowledgements This work was supported by JSPS KAKENHI (25820236) and JST PRESTO (JPMJPR15D6).

Open Access This article is distributed under the terms of the Creative Commons Attribution 4.0 International License (http://creativecommons.org/licenses/by/4.0/), which permits unrestricted use, distribution, and reproduction in any medium, provided you give appropriate credit to the original author(s) and the source, provide a link to the Creative Commons license, and indicate if changes were made.

\section{References}

Aguirregabiria, V., Mira, P.: Dynamic discrete choice structural models: a survey. J. Econ. 156, 38-67 (2010)

Akahane, H., Kuwahara, M.: A basic study on trip reservation systems for recreational trips on motorways. In: Proceedings of the of the 3rd World Congress on Intelligent Transportation Systems, pp. 1-7. ITS America, Washington (1996)

Akamatsu, T.: A system of tradable bottleneck permits for general networks. JSCE J. Infrastruct. Plan.Manag. 63(3), 287-301 (2007)

Asakura, Y., Hato, E.: Tracking survey for individual travel behaviour using mobile communication instruments. Transp. Res. Part C 12(3), 273-291 (2004)

Bellman, R.: Dynamic Programming. Princeton University Press, Princeton (1957)

Ben-Akiva, M.: The structure of travel demand models. PhD Thesis, MIT (1973)

Ben-Akiva, M., Bierlaire, M.: Discrete choice methods and their applications in short term travel decisions. In: Hall, R. (ed.) The Handbook of Transportation Science, pp. 5-33. Kluwer, Dordrecht (1999)

Berkovec, J., Stern, S.: Job exit behavior of older men. Econometrica 59, 189-210 (1991)

Daganzo, C.F., Bouthelier, F., Sheffi, Y.: Multinomial probit and qualitative choice: a computationally efficient algorithm. Transp. Sci. 11(4), 338-358 (1977) 
Das, M.: A micro econometric model of capital utilization and retirement: the case of the cement industry. Rev. Econ. Stud. 59, 287-298 (1992)

Eckstein, Z., Wolpin, K.: The specification and estimation of dynamic stochastic discrete choice models. J. Hum. Resour 24, 562-598 (1989)

Edara, P., Teodorovic, D.: Model of an advance-booking system for highway trips. Transp. Res. Part C 16(1), 36-53 (2008)

Friedman, D., Rust, J.: The Double Auction Market: Institutions, Theories, and Evidence. Addison-Wesley Publishing, Reading (1993)

Gotz, G., McCall, J.: A Dynamic Retention Model for Air Force Officers, Report R-3028-AF. The RAND Corporation, Santa Monica (1984)

Hara, Y., Hato, E.: Implementation of bicycle sharing system with tradable permits auction and behavior analysis. In: 12th World Conference on Transport Research, Lisbon, Portugal, July (2010)

Hato, E., Kitamura, R.:Data-oriented travel behavior analysis based on probe person systems. IN: TRB conference proceedings 42-Innovations in Travel Demand Modeling: Summary of a Conference, vol. 2, pp. 187-196 (2008)

He, F., Yin, Y., Shirmohammadi, N., Nie, Y.M.: Tradable credit schemes on networks with mixed equilibrium behaviors. Transp. Res. Part B 57, 47-65 (2013)

Liu, W., Yang, H., Yin, Y.: Efficiency of a highway use reservation system for morning commute. Transp. Res. Part C 56, 293-308 (2015)

McFadden, D.: Conditional logit analysis of qualitative choice behavior. In: Zarembka, P. (ed.) Frontiers in Econometrics, pp. 105-142. Academic Press, New York (1974)

McFadden, D., Train, K.: Mixed MNL models of discrete response. J. Appl. Econom. 15, 447-470 (2000)

Miller, R.A.: Job matching and occupational choice. J. Polit. Econ. 92(6), 1086-1120 (1984)

Nie, Y.M.: Transaction costs and tradable mobility credits. Transp. Res. Part B 46(1), 189-203 (2012)

Nie, Y., Yin, Y.: Managing rush hour travel choices with tradable credits scheme. Transp. Res. Part B 50, 1-19 (2013)

Pakes, A.: Patents as options: some estimates of the value of holding european patent stocks. Econometrica 54, 755-785 (1986)

Puterman, M.: Markov decision processes. In: Heyman, D.P., Sobel, M.J. (eds.) Handbooks in Operations Research and Management Science, vol. 2. Elsevier, Amsterdam (1990)

Rust, J.: Optimal replacement of GMC bus engines: an empirical model of Harold Zurcher. Econometrica 55, 999-1033 (1987)

Rust, J.: Structural estimation of Markov decision processes. In: Engle, R.E., McFadden, D. (eds.) Handbook of Econometrics, vol. 4. North-Holland, Amsterdam (1994)

Rust, J.: Numerical dynamic programming in economics. In: Amman, H., Kendrick, D., Rust, J. (eds.) Handbook of Computational Economics, vol. 1, pp. 619-729, North-Holland, Amsterdam (1996)

Shirmohammadi, N., Zangui, M., Yin, Y., Nie, Y.M.: Analysis and design of tradable credit schemes under uncertainty. Transp. Res. Food 2333, 27-36 (2013)

Smith, V.L.: Experimental economics: induced value theory. Am. Econ. Rev. 66(2), 274-279 (1976)

Teodorovic, D., Edara, P., Via, C.E.: Highway space inventory control system. In: Proceedings of the 16th International Symposium on Transportation and Traffic Theory, pp. 43-62 (2005)

Verhoef, E., Nijkamp, P., Rietveid, P.: Tradable permits: their potential in the regulation of road transport externalities. Environ. Plan. 24(4), 527-548 (1997)

Vickrey, W.: Counterspeculation, auctions, and competitive sealed tenders. J. Financ. 16(1), 8-37 (1961)

Viegas, J.M.: Making urban road pricing acceptable and effective: searching for quality and equity in urban mobility. Transp. Policy 8(4), 289-294 (2001)

Vovsha, P.: The cross-nested logit model: Application to mode choice in the Tel Aviv metropolitan area, Conference Presentation. 76th Transportation Research Board Meetings, Washington, DC., (1997)

Wada, K., Akamatsu, T.: A hybrid implementation mechanism of tradable network permits system which obviates path enumeration: an auction mechanism with day-to-day capacity control. Transp. Res. Part E 60, 94-112 (2013)

Wen, C.-H., Koppelman, F.: The generalized nested logit model. Transp. Res. Part B 35, 627-641 (2001)

Wolpin, K.: An estimable dynamic stochastic model of fertility and child mortality. J. Polit. Econ. 92, 852-874 (1984)

Wolpin, K.: Estimating a structural search model: the transition from schooling to work. Econometrica 55, 801-818 (1987)

Wong, J.T.: Basic concepts for a system advance booking for highway use. Transp. Policy 4(2), 109-114 (1997)

Wu, D., Yin, Y., Lawphongpanich, S., Yang, H.: Design of more equitable congestion pricing and tradable credit schemes for multimodal transportation networks. Transp. Res. Part B 46, 1273-1287 (2012) 
Yang, H., Wang, X.: Managing network mobility with tradable credits. Transp. Res. Part B 45(3), 580-594 (2011)

Yang, H., Liu, W., Wang, X., Zhang, X.N.: On the morning commute problem with bottleneck congestion and parking space constraint. Transp. Res. Part B 58, 106-118 (2013)

Yusuke Hara is an Assistant Professor in the Department of Civil Engineering at the University of Tokyo and a researcher of JST PRESTO. His research interests are travel behavior analysis, development of GPS trajectory analyzer for preprocessing GPS data, and mechanism design for transportation services such as car-sharing and bicycle sharing services.

Eiji Hato is a Professor in the Department of Civil Engineering at the University of Tokyo. He works in the area of travel behavior modelling, multi scale parallel simulation based on data assimilation and mobility sharing services. He has received numerous awards including honorable mention in 2002 WCTR young prize from WCTRs and 2011 Kometani-Sasaki Award from ISSR. 